\title{
The overtraining reversal effect in a probability learning situation
}

\author{
DONALD R. YELEN and DELPHINE YELEN, Washburn \\ University, Topeka, Kans. 66621
}

The present study investigated the overtraining reversal effect in a probability learning situation. Groups of $15 \mathrm{Ss}$ received either 100 or 200 training trials with either .90:.10 or 75: 25 schedules, and then received 100 trials with reversed probability schedules. There were no differences between the 100 and 200 training trial groups during the reversal trials, and thus, no evidence for an overtraining reversal effect. Previous reports of an overtraining reversal effect were attributed to differences in prereversal levels of performance.

Juola \& Hergenhahn (1967) have recently reported finding an overtraining reversal effect in a probability learning situation. In their study, Ss were given either 25 or 50 training trials with either $.90: .10, .80: .20$, or $.70: .30$ schedules, and then 100 trials with reversed probability schedules. Their results showed that $S$ s receiving 25 training trials deviated more from the expected probability levels during the reversal trials than Ss receiving 50 training trials. Since other data (e.g., Estes \& Straughan, 1954) suggest, particularly for the $.80 . .20$ and $.70: .30$ schedules, that the $S$ s would not have reached the expected probability levels with so few training trials, it is possible that little or no overtraining occurred in the Juola and Hergenhahn study and that the differences between their 25 and 50 training trials groups can be attributed to other factors.

The present experiment investigated the overtraining reversal effect in a probability learning situation where sufficient trials were given to produce stable performance levels prior to reversal.

\section{SUBJECTS}

The Ss were 60 students from introductory psychology classes at Washburn University.

\section{DESIGN}

Fifteen Ss were randomly assigned to each of the four groups that resulted from the factorial combination of two levels of training trials (100 and 200$)$ with two probability schedules $(.90: .10$ and $.75: .25)$. At the completion of training, all Ss received 100 trials with reversed probability schedules (.10:.90 and $.25: .75)$.

\section{APPARATUS}

The apparatus consisted of three horizontal lights and two toggle switches mounted on a screen separating $\mathbf{S}$ and $\mathrm{E}$. The center light was used as a signal for the $S$ to guess whether the

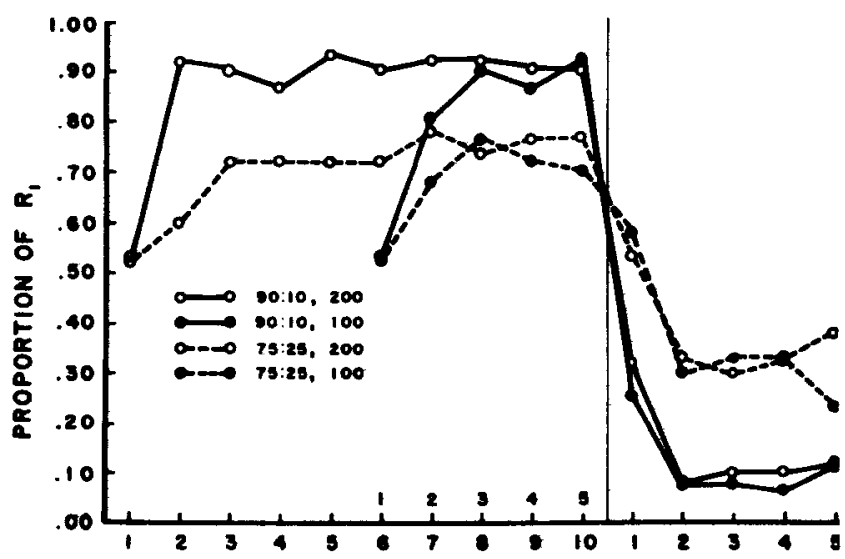

Fig. 1. Proportion of $R_{t}$ responses as a function of blocks of 20 trials. left or right light would be turned on. The Ss used the toggle switches mounted below the left and right lights to indicate their guesses. The onsets and offsets of the lights were controlled by silent Hunter timers.

\section{PROCEDURE}

Subjects were instructed that the purpose of the experiment was to "outguess" the $\mathrm{E}$ as often as possible by guessing whether $\mathrm{E}$ would turn on the left or right light. Ss were then given either 100 or 200 training trials with either $.90: .10$ or $.75: .25$ schedules. A trial consisted of the presentation of the center light for $2 \mathrm{sec}$, during which the Ss were required to indicate their guess, followed by the presentation of either the left or right light for $2 \mathrm{sec}$. The left and right lights were presented according to sequences which reproduced the probability schedules in blocks of 20 trials. During training the left light was the most frequent for seven Ss and the right light was the most frequent for eight Ss in each group. Responses to the more frequently occurring light $\left(E_{1}\right)$ were designated $R_{1}$. The training trials were followed without interruption by 100 trials with reversed probability schedules.

\section{RESULTS AND DISCUSSION}

Figure 1 presents the proportion of $R_{1}$ responses as a function of blocks of 20 trials for all four experimental groups. Inspection of the training data suggests that all four groups reached the expected probability levels. A 2 by 2 factorial analysis of variance of the reversal data yielded a significant main effect of probability schedule $(F=162.54$; $\mathrm{df}=1 / 56 ; \mathrm{p}<.01$ ), with fewer $\mathrm{R}_{1}$ responses in the group shifted to $.10: .90$ than in the group shifted to $.25: .75$. As inspection of the figure suggests, the analysis also indicated that neither the main effect of number of training trials nor the interaction of number of training trials by probability schedules were significant $(p>.20)$. Thus, the present study demonstrates no evidence of an overtraining reversal effect in a probability learning situation.

The discrepancy between the results of the present study and data presented by Juola \& Hergenhahn (1967) suggests that reversals in a probability learning situation for a given probability schedule may be a function of the prereversal level of performance. That is, the closer $R_{1}$ approaches the probability of $E_{1}$ during prereversal trials, the faster the reversal. In the present study, $R_{1}$ responses in both of the $.90: .10$ groups and in both of the $.75: .25$ groups approached the $\mathrm{E}_{1}$ probability levels before the reversal was introduced. In the Juola and Hergenhahn study, however, it was likely, first, that $R_{1}$ responses, at least in the $.80: .20$ and $.70: .30$ groups, did not reach the $E_{1}$ probability levels before the reversal was introduced, and second, that the $R_{1}$ responses for groups receiving 50 training trials were closer to the $E_{1}$ probability levels than for groups receiving 25 training trials. When Ss receiving the same probability schedule reach the same prereversal level of performance, as in the present experiment, different numbers of training trials have no effect on the rate of reversal. However, when different prereversal levels of $R_{1}$ are reached because of different numbers of training trials, as is likely for some groups in the Juola and Hergenhahn study, the groups whose $R_{1}$ performance most closely approaches the probability of $E_{1}$ will reverse faster.

\section{REFERENCES}

ESTES W $K$ \& STRAUGHAN, J. H Analysis of a verbal conditioning situation in terms of statistical learning theory. Journal of Experimental Psychology, 1954, 47, 225-234.

JUOLA, J. F., \& HERGENHAHN, B. R. Probability matching and the overlearning reversal effect. Psychonomic Science, 1967, 8, 309-310. 